\title{
NdYAG laser photocoagulation in the dog stomach
}

\author{
S G BOWN,* P R SALMON, D W STOREY, B M CALDER, D F KELLY $\dagger$ \\ N ADAMS, H PEARSON, AND B M Q WEAVER \\ From The Rayne Institute, University College Hospital Medical School, London, and the Departments of \\ Medicine, Pathology and Veterinary Surgery, University of Bristol, Bristol
}

SUMMARY Considerable discussion still centres around the relative merits of the Argon and Neodymium Yttrium Aluminium Garnet (NdYAG) lasers for the endoscopic treatment of gastrointestinal haemorrhage, although both are undoubtedly effective. We have carried out experiments to elucidate which factors determine the safety and efficacy of NdYAG laser photocoagulation. Histological studies on normal gastric mucosa showed that the depth of tissue damage depended mainly on the total incident laser energy, whereas the effectiveness of photocoagulation of induced gastric ulcers in heparinised animals depended on the laser power and the exposure time used. Optimum haemostasis with minimum tissue damage was obtained using pulses of 300 to 500 ms duration with energies of 25 to $40 \mathrm{~J}$. We consider these parameters safe and effective for use in pilot clinical studies.

High power Argon ion and NdYAG lasers have been available for several years. Both are suitable for photocoagulation in the gastrointestinal tract as the beam from each may be transmitted via a single quartz fibre which can be passed down the biopsy channel of an endoscope. However, the different wavelengths lead to considerable differences in the absorption patterns in living tissue.

The blue green Argon beam has a high absorption coefficient, so that the intensity of the light drops off very rapidly as the beam passes deeper into the tissue. Histological changes are detectable for a depth of only about $1 \mathrm{~mm}$ below the surface exposed to the laser, although, if the energy applied is sufficient to destroy the superficial layers, changes are detectable for $1 \mathrm{~mm}$ below the base of the ensuing hole. ${ }^{1}$ In contrast, the infra-red beam of the NdYAG laser (wavelength $1060 \mathrm{~nm}$ ) has a much lower absorption cofficient, so the intensity of the beam drops off less rapidly as the beam penetrates deeper. Deeper effects are detectable histologically before destruction of superficial layers occurs. The lower absorption coefficient for the YAG radiation means that for the same amount of energy to be absorbed in the surface area where coagulation is required, a 10-fold

*Address for correspondence: S G Bown, The Rayne Institute, University College Hospital Medical School, University Street, London WC1E 6JJ.

†Present address: Department of Veterinary Pathology, University of Liverpool.

Received for publication 28 May 1980 greater incident energy is required than with the Argon beam. The rest of the energy is reflected from the surface, transmitted or absorbed in the deeper layers.

For several years there has been extensive discussion on the relative effectiveness and safety of the two lasers. Some authors report that the YAG is more effective as the greater penetration enables larger blood vessels to be coagulated, and that the risks are low. ${ }^{2}$ In contrast, others report a high risk of full-thickness damage in experiments with the YAG laser on induced bleeding ulcers in the dog stomach. ${ }^{3}$ It is the depth of penetration of the YAG beam that has given rise to most concern.

The main reason for this continued controversy is a lack of detailed knowledge of the parameters which determine the safety and efficacy of photocoagulation, and what the optimum values for these parameters are. We have previously reported such studies with an Argon laser system ${ }^{14}$ and in this paper present a similar study with the NdYAG laser.

\section{Methods}

We used four different NdYAG laser systems in these experiments: the MBB Medilas, Molectron 8000, CiLas YAG Medical 100, and a special pulsed NdYAG system provided by J K Lasers Ltd. The first three are basically continuous wave systems, whereas the $\mathrm{J} \mathrm{K}$ laser can deliver pulses of duration 50 to $1000 \mathrm{~ms}$. In early experiments with the Medilas 

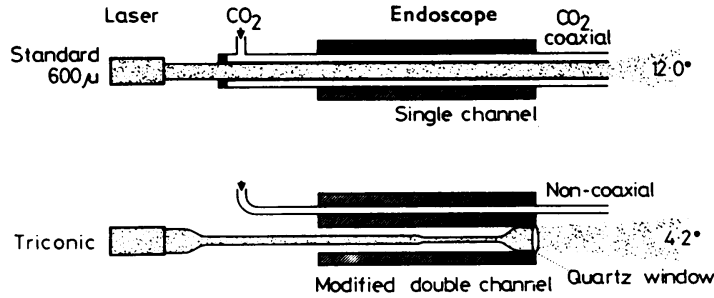

Fig. 1 Quartz transmission fibres.

system, we compared two different transmission fibres, although, in later experiments with the other laser systems, used only the 600 micron standard fibre with coaxial gas. The two fibres are shown in Fig. 1. The wide proximal end of the triconic fibre facilitates coupling to the laser (although we obtained $80-85 \%$ transmission of the laser power with each fibre), while the 300 microns central section ensures adequate flexibility in the endoscope with a short narrower section (200 microns) to correspond to the last section of the endoscope where flexion angles are the greatest. The design of the wide distal tip of the fibre reduces the angle of divergence of the emitted beam. However, the delicate nature of the triconic fibre requires that it be fitted permanently in a two-channel endoscope, and that the distal end of the biopsy channel used be modified so that a small quartz window can be fitted to prevent blood or secretions contaminating the fibre tip. If the laser is fired when the fibre tip is contaminated, the tip is destroyed and the fibre is ruined. The small quartz window is replaceable, although, to reduce the risk of damage, the lens washing channel of the. endoscope is modified to wash the extra window as well. This closed system makes it impossible to use a stream of $\mathrm{CO}_{2}$ gas fully coaxial with the laser beam to clear the blood from the lesion being treated, and the tip of the fibre cannot be moved beyond the tip of the endoscope, although a separate catheter for $\mathrm{CO}_{2}$ or saline washing can be passed via the second biopsy channel. The 600 micron fibre is much cheaper and simpler to handle. If the tip is damaged, the fibre can be cleaved proximal to the damaged area and used again as it has a constant cross-section. In addition, it can be passed through a $2 \mathrm{~mm}$ plastic catheter, permitting the use of a coaxial stream of $\mathrm{CO}_{2}$ gas for clearing the area under examination, and the combination may be passed down (and beyond the end of) the biopsy channel of a one or two channel endoscope without previous modification of the instrument. The tip of the fibre is more vulnerable to contamination, but protection against this is achieved by keeping the tip 1-2 mm inside the end of the plastic catheter and maintaining a slow background flow of $\mathrm{CO}_{2}$ gas which prevents secretions entering the catheter. The rapid flow of $\mathrm{CO}_{2}$ gas is initiated separately when required to blow blood out of the field of view. The disadvantage of the 600 micron fibre is that the angle of divergence of the emitted beam is greater.

As the main YAG beam is invisible, aiming is accomplished using a low power helium-neon laser, which produces a red light. This is transmitted by the same fibre, and produces an aiming beam with the same divergence as that of the infra-red YAG beam. The YAG power is set by varying the laser lamp current and checked at the distal end of the fibre by a separate power meter before use.

Adequate safety precautions are essential and these were taken under the supervision of the University Safety Officers.

Studies were carried out on 16 dogs at laparotomy and gastrotomy under a balanced general anaesthetic protocol, analgesic administration being continued into the postoperative period in recovery experiments. All quantitative histological studies of the extent of tissue damage were carried out on dogs weighing $8-15 \mathrm{~kg}$, all but one of which were beagles.

The first phase of the study was designed to determine the factors which influence the extent of tissue damage produced by the laser. To do this, single lesions were made on normal gastric mucosa, varying the laser power from 25 to $75 \mathrm{~W}$ and the exposure time from one to five seconds. In these experiments, the beam divergence was kept at a full angle of 11 degrees, and lesions were made with the fibre tip situated 5,10 and $20 \mathrm{~mm}$ from the mucosa.

Animals in which these lesions had been made were killed either within two hours of exposure to the laser, or after four days. Each spot was identified by suture markers, and, after fixing in formalin, histological sections made through the centre of each spot, and stained with haematoxylin and eosin. These were examined microscopically using a graticule eyepiece to measure the maximum depth of damage. This was expressed as a percentage of the thickness of the layer in which the deepest damage was seen (mucosa, submucosa, or muscularis propria). Lesions extending to the serosa were regarded as full thickness.

The second phase of the study was to assess the haemostatic effect of the laser, and, to do this, gastric ulcers were made with the Quinton ulcer maker $^{5}$ at gastrotomy. This instrument produces ulcers of a standard depth, so enabling the extent of any further damage produced by laser treatment to be readily assessed. These experiments were performed on heparinised animals, a check always being made that untreated control ulcers continued to bleed throughout the minimum observation time (three minutes). The blood loss was quantified by 
collection in wide mouthed vials from the edge of each ulcer for the first minute after it was made, (and an additional collection made in the third minute for untreated control ulcers). Each ulcer was then treated with the laser, using repeated short pulses, until haemostasis was obtained. If four pulses on any one bleeding point in an ulcer failed to stop the bleeding or it became apparent that additional pulses were causing increasing tissue damage with no improvement in haemostasis or a total of 20 pulses had been applied to an ulcer without complete haemostasis, photocoagulation was considered to have failed.

Initially, only one second laser pulses were used, and the fibre tip was held approximately $10 \mathrm{~mm}$ above the bleeding point. Ulcers were treated with laser powers from 25 to $66 \mathrm{~W}$ and a comparison made between the 600 micron fibre with a truly coaxial stream of $\mathrm{CO}_{2}$ gas, and the triconic fibre fixed in a two-channel endoscope with a separate catheter for $\mathrm{CO}_{2}$ to clear the blood being passed down the second biopsy channel. When the laser power was increased to over $70 \mathrm{~W}$, it became apparent that effective haemostasis was achieved on individual bleeding spots in times well below one second. Consequently, a further series of experiments was carried out studying pulse lengths in the range 50 to

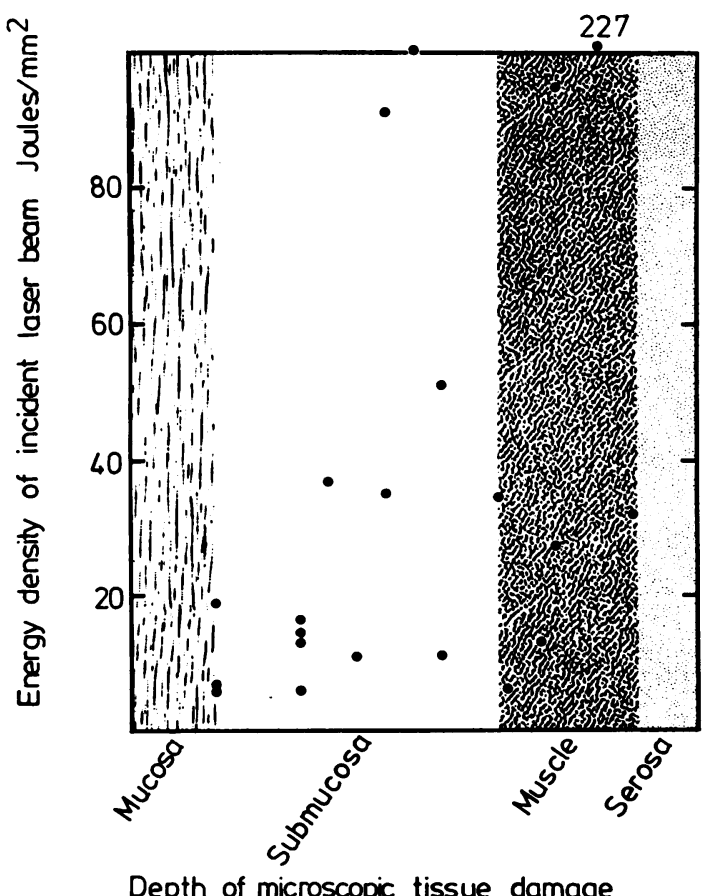

Fig. 2 Normal gastric mucosa. Effect of energy density on depth of histological damage in acute lesions.
$700 \mathrm{~ms}$ with pulse energies (energy $=$ power $\times$ exposure time) from 15 to $40 \mathrm{~J}$. For these experiments, only the 600 micron fibre was used.

Treated ulcers were marked with sutures and excised after the animals were killed at times between one hour and one month after treatment. Each site was then examined histologically.

\section{Results}

NORMAL MUCOSA

Initial studies showed that at any particular power level and fibre-mucosa distance, the width and depth of the lesions produced on normal gastric mucosa increased steadily with the time of exposure. Consequently, detailed analysis was performed using the energy of the laser beam (=power $\times$ time) rather than the power alone. For each lesion made on normal gastric mucosa at various values of the laser power, exposure time, and fibre-mucosa distance, the energy density on the tissue surface and the total laser energy were calculated and plotted against the depth of microscopic tissue damage. These results are shown in Figs. 2 and 3 for acute lesions, the tissue being fixed within two hours of exposure to the laser beam. Figure 2 shows that there is a

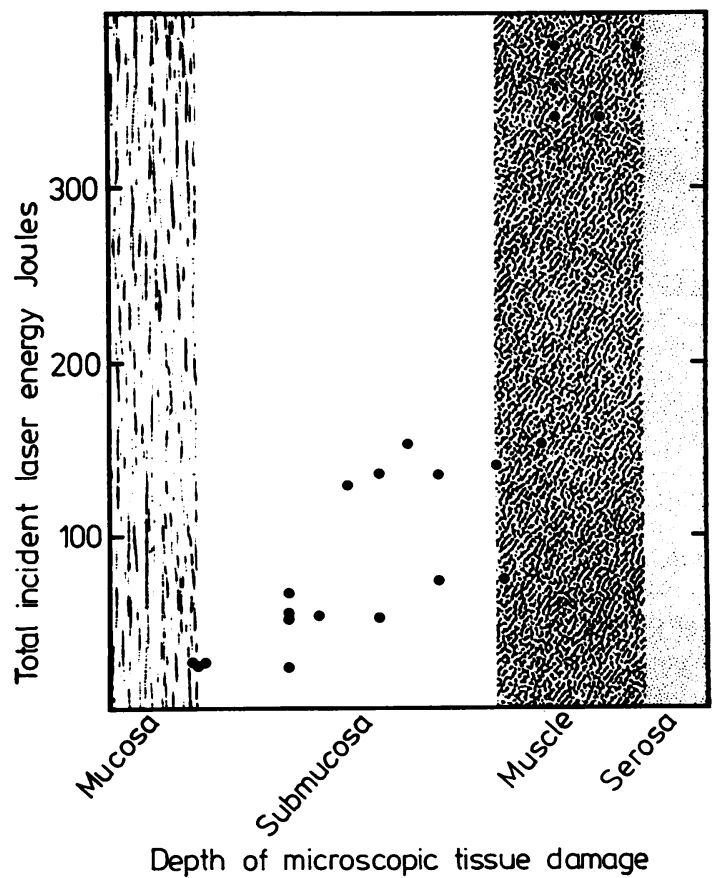

Fig. 3 Normal gastric mucosa. Effect of total energy on depth of histological damage in acute lesions. 


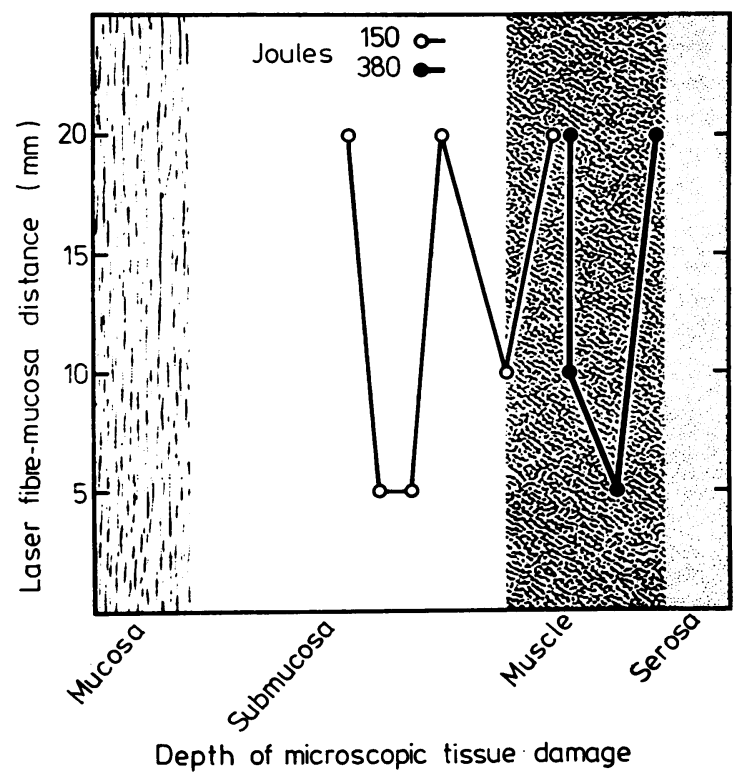

Fig. 4 Normal gastric mucosa. Effect of fibre-mucosa distance on depth of histological damage in acute lesions. The lines link points representing lesions made with the same total energy.

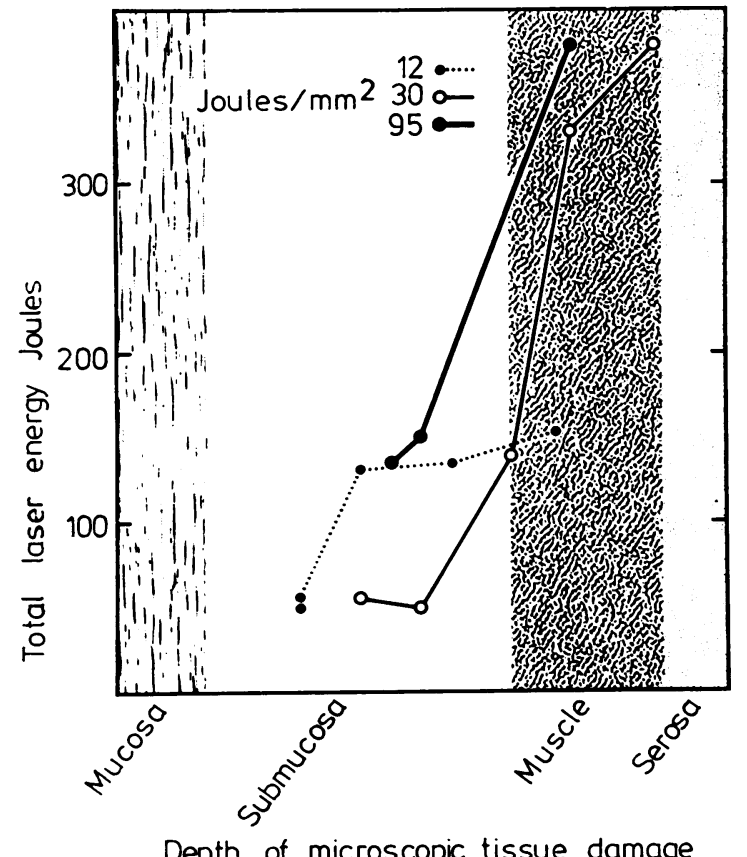

Fig. 5 Normal gastric mucosa. Effect of total energy on depth of histological damage in acute lesions. The lines link pointsrepresenting lesions made with the same energy density. general tendency for the depth of damage to increase as the energy density increased, but there are marked anomalies. Two points are shown with energy densities over $80 \mathrm{~J} / \mathrm{mm}^{2}$, in which the damage does not reach the external muscle layer; however, several other muscle lesions result from energy densities below $40 \mathrm{~J} / \mathrm{mm}^{2}$. In contrast, Fig. 3 shows a steady increase in the extent of damage with increasing total energy, without the anomalies seen in Fig. 2, suggesting that within the range of values studied, the total energy is a more important parameter than the energy density. This is brought out more clearly in Figs 4. and 5. Fig. 4 shows the poor correlation between the fibre-mucosa distance and the depth of damage at two different energy levels, whereas in Fig. 5 there is a much closer correlation between the total energy and the depth of damage. This is largely independent of the energy density, as the lines for the three different values of energy density all cross each other. Figure 6 shows measurements of the width of these lesions as measured on the mucosa. To eliminate any possible effect from varying pulse lengths, only lesions made with five second exposures are plotted. The diameter of the beam on the tissue at each fibre-mucosa distance is shown on the left of the Figure. The width of the lesions increases with the total energy and is independent of the spot size of the beam on the tissue as the curves for the two different spot sizes are virtually identical.

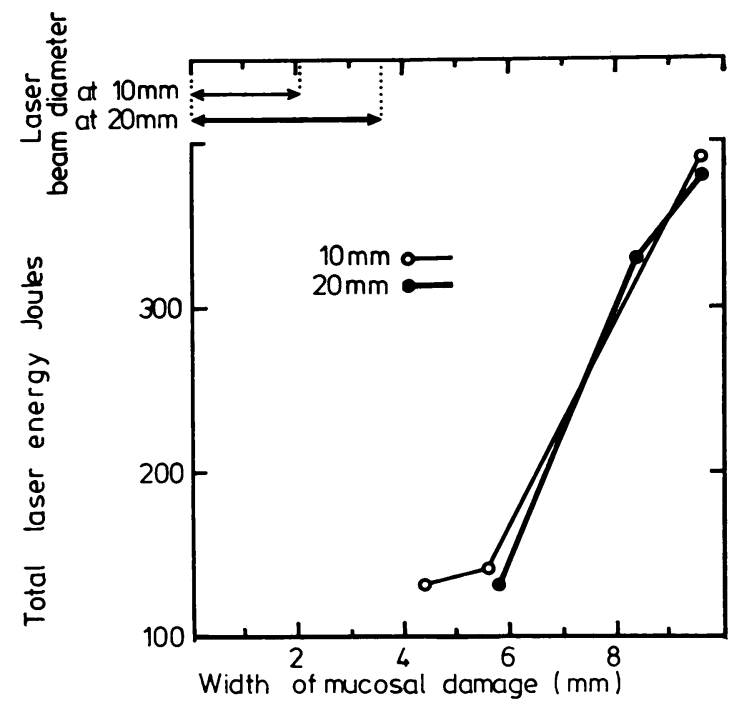

Fig. 6 Normal gastric mucosa. Effect of total energy on width of mucosal damage in acute lesions. The lines link points representing lesions made with the same spot size. 
Table 1 Comparison of transmission fibres using one second laser pulses

\begin{tabular}{|c|c|c|c|c|c|}
\hline \multirow[t]{2}{*}{ Fibre } & \multirow{2}{*}{$\begin{array}{l}\text { Power } \\
(W)\end{array}$} & \multirow{2}{*}{$\begin{array}{l}\text { Ulcers } \\
\text { (no.) }\end{array}$} & \multicolumn{2}{|c|}{ Haemostasis } & \multirow{2}{*}{$\begin{array}{l}\text { Mean energy } \\
\text { for successful } \\
\text { haemostasis } \\
(J)\end{array}$} \\
\hline & & & (no.) & $(\%)$ & \\
\hline \multirow[t]{2}{*}{ Triconic } & 45 & 6 & 3 & 50 & 705 \\
\hline & 65 & 6 & 5 & 83 & 475 \\
\hline \multirow[t]{2}{*}{600 micron } & 45 & 6 & 5 & 83 & 430 \\
\hline & 55 & 5 & 6 & 100 & 320 \\
\hline
\end{tabular}

INDUCED BLEEDING ULCERS

All untreated control ulcers were still bleeding at the end of the three minute observation period. Blood loss from these in the first minute varied between 0.1 and $2.5 \mathrm{ml}$ and in the third minute from 0.05 to $1.35 \mathrm{ml}$. For every control ulcer, blood loss in the third minute was at least $50 \%$ of the loss in the first minute. Blood loss in the first minute from ulcers subsequently treated averaged $1.35 \mathrm{ml}$.

\section{EFFECTS OF PHOTOCOAGULATION}

The results of the experiments comparing the triconic fibre with the 600 micron fibre are shown in Table 1. These suggest that the 600 micron fibre is slightly better in terms of the effectiveness of coagulation and the mean energy (pulse energy $\times$ mean number of pulses used) at each power for successful coagulation, although the differences are not statistically significant. However, other factors led us to prefer the 600 micron fibre. It was much easier to identify and coagulate the exact bleeding spot using a truly coaxial stream of $\mathrm{CO}_{2}$ gas, it was easier to handle

Table 2 Haemostatic effect of photocoagulation

\begin{tabular}{|c|c|c|c|c|}
\hline \multicolumn{2}{|l|}{ Pulse: } & \multirow[b]{2}{*}{$\begin{array}{l}\text { Ulcers } \\
\text { (no.) }\end{array}$} & \multicolumn{2}{|c|}{ Haemostasis } \\
\hline $\begin{array}{l}\text { Length } \\
(m s)\end{array}$ & $\begin{array}{l}\text { Energy } \\
(J)\end{array}$ & & (no.) & $(\%)$ \\
\hline 50 & 25 & 2 & 0 & $\overline{2 e}$ \\
\hline 50 & 30 & 4 & 1 & 25 \\
\hline 100 & 20 & 2 & $\mathbf{0}$ & - \\
\hline 100 & 30 & 5 & 1 & 20 \\
\hline 200 & 15 & 4 & $\mathbf{0}$ & - \\
\hline 200 & 20 & 6 & 3 & 50 \\
\hline 200 & 25 & 7 & 7 & 100 \\
\hline 200 & 30 & 10 & 9 & 90 \\
\hline 200 & 40 & 3 & 3 & 100 \\
\hline 300 & 15 & 3 & 1 & 33 \\
\hline 300 & 20 & 4 & 4 & 100 \\
\hline 300 & 25 & 3 & 3 & 100 \\
\hline 300 & 30 & 12 & 9 & 75 \\
\hline 300 & 40 & 13 & 10 & 77 \\
\hline 400 & 30 & 9 & 8 & 89 \\
\hline 400 & 40 & 8 & 8 & 100 \\
\hline 500 & 15 & 3 & $\mathbf{0}$ & $\overline{0}$ \\
\hline 500 & 25 & 3 & 3 & 100 \\
\hline 500 & 30 & 7 & 6 & 86 \\
\hline 500 & 40 & 3 & 3 & 100 \\
\hline 700 & 35 & 4 & 4 & 100 \\
\hline 1000 & 25 & 5 & 3 & 60 \\
\hline 1000 & 45 & 6 & 5 & 83 \\
\hline 1000 & 55 & 5 & 5 & 100 \\
\hline
\end{tabular}

Table 3 Combined results for all pulse energies from 20 to 55 joules

\begin{tabular}{lccc}
\hline $\begin{array}{l}\text { Pulse length } \\
\text { (ms) }\end{array}$ & $\begin{array}{l}\text { Ulcers } \\
\text { (no.) }\end{array}$ & \multicolumn{2}{c}{ Haemostasis } \\
\cline { 3 - 4 } & 6 & $($ no. $)$ & $(\%)$ \\
100 & 6 & 1 & 17 \\
200 & 7 & 1 & 14 \\
300 & 26 & 22 & 85 \\
400 & 32 & 16 & 81 \\
500 & 17 & 12 & 94 \\
700 & 13 & 4 & 100 \\
1000 & 4 & 13 & 81 \\
\hline
\end{tabular}

the coaxial gas system, and on one occasion, when the quartz protective window over the tip of the triconic fibre was changed, unrecognised misalignment occurred and the tip of the endoscope became very hot when the laser was fired, risking damage to the endoscope. These reasons, together with those outlined above, led us to abandon the triconic fibre and all subsequent experiments were carried out using a 600 micron fibre with coaxial gas.

The results of experiments, carried out using pulses from 50 to $1000 \mathrm{~ms}$ (excluding those with the triconic fibre) are shown in Table 2. The values used for the pulse duration and pulse energy reflect the range of outputs obtainable from the four different NdYAG lasers used. At a pulse energy of $15 \mathrm{~J}$, it was possible to stop bleeding in only one out of 10 ulcers (for pulse lengths $200-500 \mathrm{~ms}$ ). This is significantly less than the 76 out of 88 stopped with pulse energies of 20 to $40 \mathrm{~J}$ with the same pulse lengths $(P<0.001)$. There is no significant difference between the numbers stopped at $20,25,30$, and $40 \mathrm{~J}$. At pulse lengths of $50 \mathrm{~ms}$ and $100 \mathrm{~ms}$ only one out of six and one out of seven ulcers respectively were successfully photocoagulated. This is significantly less than the 55 out of 66 photocoagulated at the same pulse energies $(20,25,30 \mathrm{~J})$ with pulse durations of 200 to $1000 \mathrm{~ms}(\mathrm{P}<0.001)$. The total number of ulcers coagulated at each pulse length is shown in Table 3. There is no significant difference between the success rates at $200,300,400,500,700$, and $1000 \mathrm{~ms}$.

The mean energies required for successful haemostasis in experimental ulcers using pulses of 25 , 30, and $40 \mathrm{~J}$ are shown in Fig. 7. There was a wide variation in the number of pulses used at each value of pulse length and energy, and the differences shown do not reach statistical significance. However, certain trends are suggested: (1) the total mean energies are greater at higher values of the individual pulse energy; (2) the mean energies are lower with pulse lengths in the range 300 to $500 \mathrm{~ms}$ than at longer or shorter times.

None of the successfully treated ulcers bled again 


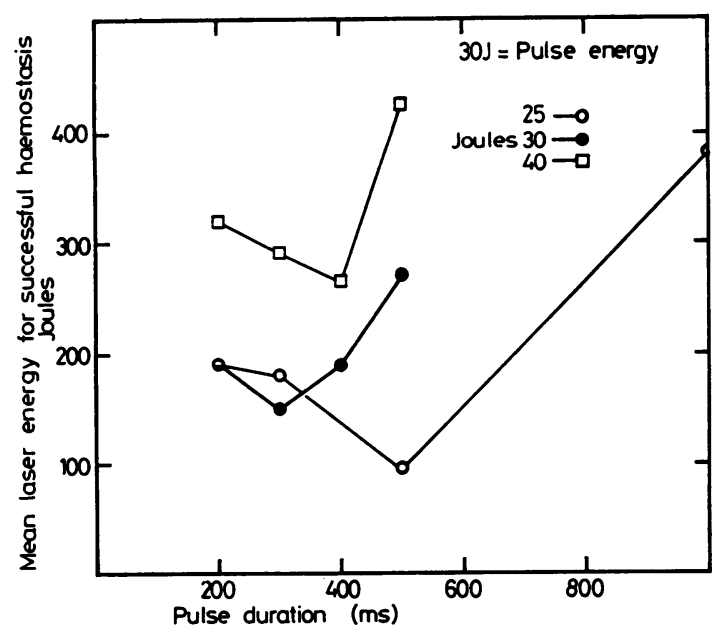

Fig. 7 Effect of pulse length and pulse energy on mean energy for haemostasis in induced ulcers.

in the first minute after treatment. However, some bled again after a longer period and this depended largely on mechanical factors (disturbance of the coagulum over a treated ulcer by handling of the stomach) which were extremely difficult to quantify. Nevertheless, certain empirical observations could be made:

1. The coagulum appeared to be most firmly attached after treatment with pulse lengths of

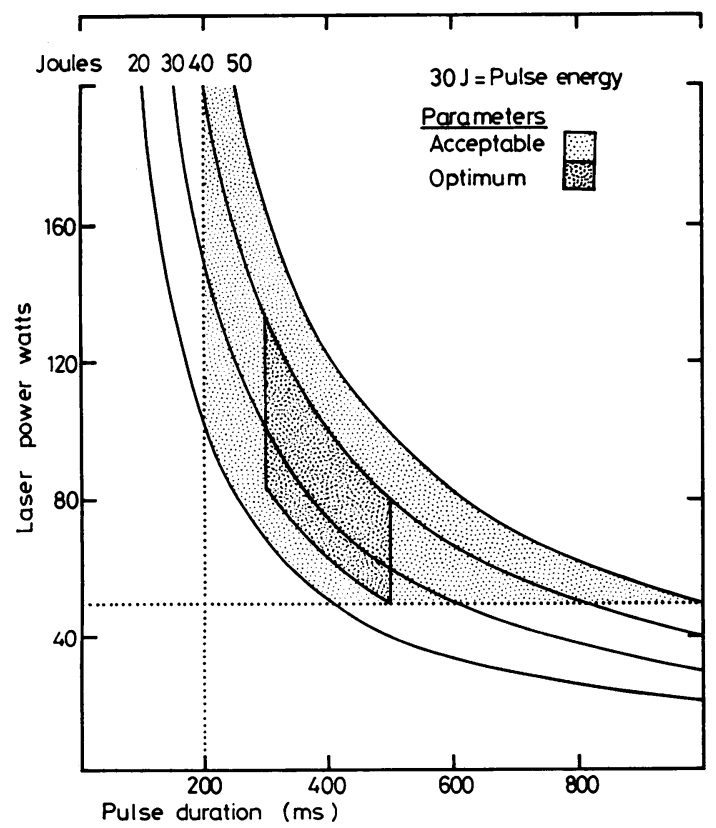

Fig. 8 The limits on pulse parameters for safe, effective photocoagulation of induced ulcers.
$300-500 \mathrm{~ms}$, and less firm with pulses of 200 and $1000 \mathrm{~ms}$ duration at similar energies (although higher energy pulses at $1000 \mathrm{~ms}(55 \mathrm{~J})$ did produce a better coagulum).

2. Palpation of treated ulcers between two fingers showed a definite firmness of the tissue in those with a good coagulum, not present in those with only a loosely adherent coagulum.

3. Ulcers treated with laser powers up to $50 \mathrm{~W}$ $(25,45 \mathrm{~J}$ at $1000 \mathrm{~ms}, 25 \mathrm{~J}$ at $500 \mathrm{~ms})$ were more likely to bleed again than those treated at higher powers.

4. Most ulcers were treated by keeping the fibre tip approximately $10 \mathrm{~mm}$ from the bleeding point, and with the beam perpendicular to the tissue. However, pilot studies varying the angle of the beam to the tissue (from 30 to $90^{\circ}$ ) and the distance of the fibre tip from the tissue (up to $20 \mathrm{~mm}$ ) showed that neither of these factors influences the effectiveness of photocoagulation. The fact that neither the depth of tissue damage nor the effectiveness of photocoagulation depend on the distance between the fibre tip and the tissue using the $11^{\circ}$ divergence of the beam from the $600 \mu$ fibre (within the range of values studied) shows that the main positive feature of the triconic fibre-namely, the low divergence $\left(4 \cdot 2^{\circ}\right)$ of the emitted beam-is not of any practical importance in this application.

Histological studies of ulcers treated one to two weeks before the animals were killed showed fullthickness damage to the stomach wall in four out of five in which the total energy used was greater than $250 \mathrm{~J}$, but in none of the five treated with energies below $200 \mathrm{~J}$. No perforations occurred. Full details of the pathological changes seen are to be published separately.

The results are summarised in Fig. 8. Although we consider the hatched area to represent the optimum parameters, values in the speckled area produced good haemostasis with acceptable degrees of tissue damage. The loss of effectiveness below $20 \mathrm{~J}$ was so marked that $25 \mathrm{~J}$ was chosen as the lower limit of the optimum range to give a reasonable margin for error. The upper limit for pulse energy at $40 \mathrm{~J}$ is much less well defined. Higher energies are effective, but the extent of tissue damage steadily increases as the pulse energy rises.

\section{Discussion}

Although the absorption characteristics of Argon and NdYAG laser radiation in the dog stomach are well understood, no detailed studies have been reported of the factors which determine the extent of tissue damage produced by NdYAG laser radiation. Kiefhaber et al. ${ }^{2}$ state that the volumes of laser- 
induced tissue coagulation depend on the applied energy. However, they express the critical value required for perforation in a dog stomach (thickness $2 \mathrm{~mm}$ ) as an energy density of $14000 \mathrm{~J} / \mathrm{cm}^{2}$. Other investigators have kept the exposed tissue area constant for different lesions created on normal mucosa, so keeping constant the ratio of energy to energy density which prevents a separation of the effects of the two. ${ }^{6}$ Our present studies show that, in lesions studied on the day of exposure, the total laser energy is more important than the energy density in determining the depth and width of tissue damage. This is similar to our previous observations with the Argon laser. ${ }^{4}$ In the present experiments, studies on animals which survived for four days proved difficult, as all lesions produced with a total energy over $100 \mathrm{~J}$ showed some evidence of fullthickness damage, although this was often patchy. Furthermore, the lesions produced with lower energies showed such minor mucosal changes that it was difficult to identify and localise the area of deepest damage. All damage must have been initiated at the time of exposure, so we concluded that the acute changes were only the most severe ones and that lesser degrees of damage do not become visible histologically for several days. However, we feel that this does not invalidate the above conclusion, as the extent of severe damage is likely to be closely related to the extent of all damage.

Having established that the depth of tissue damage depends mainly on the total laser energy applied to any one spot, the aim of the photocoagulation experiments was to establish the optimum parameters for effective haemostasis with minimum energy deposition. In our model, the total energies measured were those applied to the entire area of each ulcer, and not to individual bleeding points, but it is not possible to measure the energies on individual spots when additional shots are applied to adjacent, overlapping areas. However, it is reasonable to expect that the treatment parameters that minimise the total energy for arresting haemorrhage from an ulcer will also minimise the energy deposited on any one spot (which is the factor determining the risk of full-thickness damage, and consequently of perforation). This has been borne out in our histological studies which showed that the treated ulcers with no evidence of full-thickness damage were those that received low total energies. The significance of patchy, full-thickness necrosis without perforation, as seen in some of our chronic studies, is open to debate, although Dixon et al. ${ }^{7}$ have produced perforation with $\mathbf{4 4 0} \mathrm{J}$ on one spot over eight seconds in a similar model. Consequently, it is difficult to give an exact figure for the amount of energy that can safely be deposited on any one spot, as this also depends on the nature and depth of the tissue surrounding the bleeding point. Our ulcer model can only be compared directly with acute gastric and duodenal ulcers in man, but as a working guide, we consider treatment of each bleeding point with up to four pulses of 25-40 J, and duration 300 to $500 \mathrm{~ms}$ to be safe. However, in practice, haemostasis is best when achieved with a single shot on each spot. The main limiting factor to effective treatment is the diameter of the bleeding vessel, and, in experimental studies, the limit for the NdYAG laser is vessels up to $3 \mathrm{~mm}$ in diameter. ${ }^{8}$ This covers all important sources of haemorrhage in the upper gastrointestinal tract except varices, which remain a major problem. Much more work is required to establish whether lasers have a role to play in stopping variceal haemorrhage.

Previous publications have reported the use of pulse durations of only one second or longer, and these showed a high incidence of full-thickness tissue damage in careful histological studies ${ }^{3}$ and some instances of perforation have occurred in clinical use. ${ }^{2}$ We consider that the optimum parameters described in this paper provide good haemostasis with an acceptable degree of tissue damage and are appropriate for use in pilot clinical studies. Now that safe and effective parameters have been established for both the Argon ion and NdYAG lasers, it should be possible to compare their relative merits in clinical use.

We should like to thank Professor G H Arthur and the staff of the Department of Veterinary Surgery, University of Bristol and Professor J D Judah and the staff of the Department of Experimental Pathology, University College Hospital Medical School, London, for their help and advice throughout this project. Experiments with the Cilas laser were carried out in France with Dr J M Brunetaud, of the University Hospital, Lille. We should also like to thank Mr M Adamson and J K Lasers Ltd for their expertise with the $\mathbf{J} \mathrm{K}$ laser, Mr D A Pyser and Pyser Ltd for their support with the Molectron laser, Mr P Taylor and Brocades (Great Britain) Ltd for their support with the Medilas system and the Safety Officers of the University of Bristol and University College Hospital, London. The work was carried out with the support of a grant from the Department of Health and Social Security.

\section{References}

${ }^{1}$ Kelly DF, Bown SG, Salmon PR, Calder BM, Pearson $H$, Weaver BMQ. The nature and extent of histological changes induced by argon laser photocoagulation in canine gastric mucosa. Gut (in press). 
${ }^{2}$ Kiefhaber P, Nath G, Moritz K. Endoscopical control of massive gastrointestinal hemorrhage by irradiation with a high-power Neodymium-YAG laser. Prog Surg 1977; 15: 140-55.

${ }^{3}$ Protell RL, Silverstein FE, Auth DC, Dennis MB, Gilbert DA, Rubin CE. The Nd:YAG laser is dangerous for photocoagulation of experimental bleeding gastric ulcers when compared with the argon laser. Gastroenterology 1978; 74: 1080 (Abstract).

${ }^{4}$ Bown SG, Salmon PR, Kelly DF, et al. Argon laser photocoagulation in the dog stomach. Gut 1979; 20: 680-7.

${ }^{5}$ Protell RL, Silverstein FE, Piercey J, Dennis $M$, Sprake W, Rubin CE. A reproducible animal model of acute bleeding ulcer - the 'ulcer maker'. Gastroenter- ology 1976; 71 : $961-4$.

${ }^{6}$ Fruhmorgen P, Kaduk B, Reidenbach HD, Bodem F, Demling $K$. Comparative investigations on fibreendoscopic photocoagulation with an Argon-ion and a Neodymium YAG laser. VIII Congress on Gastroenterological Endoscopy. W. Germany: Travemunde, 1976.

'Dixon JA, Berenson MM, McCloskey DW. Neodymium-YAG laser treatment of experimental canine gastric bleeding. Gastroenterology 1979; 77: 647-51.

${ }^{8}$ Leheta F, Gorisch W. Coagulation of blood vessels by means of argon ion and NdYAG laser radiation. Proceedings of 1st International Symposium on Laser Surgery. Israel, November 1975. Jerusalem: Jerusalem Academic Press, 1975: 178-84. 